\title{
Infections, antibiotic treatment and mortality in patients admitted to ICUs in countries considered to have high levels of antibiotic resistance compared to those with low levels
}

Håkan Hanberger ${ }^{1}$, Massimo Antonelli ${ }^{2}$, Martin Holmbom', Jeffrey Lipman ${ }^{3}$, Peter Pickkers ${ }^{4}$, Marc Leone ${ }^{5}$, Jordi Rello ${ }^{6}$, Yasser Sakr ${ }^{7}$, Sten M Walther ${ }^{8}$, Philippe Vanhems ${ }^{9}$, Jean-Louis Vincent ${ }^{10^{*}}$ and for the EPIC II Group of Investigators

\begin{abstract}
Background: Antimicrobial resistance is an increasing concern in ICUs worldwide. Infection with an antibiotic resistant (ABR) strain of an organism is associated with greater mortality than infection with the non-resistant strain, but there are few data assessing whether being admitted to an intensive care unit (ICU) with high levels of antimicrobial resistance is associated with a worse outcome than being admitted to an ICU with low rates of resistance. The aim of this study was, therefore, to compare the characteristics of infections and antibiotic treatments and patient outcomes in patients admitted to ICUs in countries considered as having high levels of antibiotic resistance and those admitted to ICUs in countries considered as having low levels of antibiotic resistance.

Methods: Data from the large, international EPIC II one-day point prevalence study on infections in patients hospitalized in ICUs were used. For the current study, we compared the data obtained from patients from two groups of countries: countries with reported MRSA rates of $\geq 25 \%$ (highABR: Greece, Israel, Italy, Malta, Portugal, Spain, and Turkey) and countries with MRSA rates of < 5\% (lowABR: Denmark, Finland, Netherlands, Norway, and Sweden).

Results: On the study day, 1187/2204 (53.9\%) patients in the HighABR ICUs were infected and 255/558 (45.7\%) in the LowABR ICUs ( $P<0.01)$. Patients in the HighABR ICUs were more severely ill than those in the LowABR ICUs, as reflected by a higher SAPS II score (35.6 vs 32.7, P < 0.05) and had longer median ICU (12 days vs 5 days) and hospital (24 days vs 16 days) lengths of stay. They also had higher crude ICU (20.0\% vs 15.4\%) and hospital (27.0\% vs $21.5 \%)$ mortality rates (both $\mathrm{P}<0.05$ ). However, after multivariable adjustment and matched pair analysis there were no differences in ICU or hospital mortality rates between High or LowABR ICU patients overall or among those with infections.
\end{abstract}

Conclusions: Being hospitalized in an ICU in a region with high levels of antimicrobial resistance is not associated per se with a worse outcome.

Keywords: Infection, Critically ill, Antibiotic, Resistance

\footnotetext{
* Correspondence: jlvincen@ulb.ac.be

${ }^{10}$ Department of Intensive Care, Erasme Hospital, Université Libre de

Bruxelles, Brussels, Belgium

Full list of author information is available at the end of the article
}

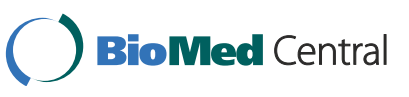

(c) 2014 Hanberger et al.; licensee BioMed Central Ltd. This is an Open Access article distributed under the terms of the Creative Commons Attribution License (http://creativecommons.org/licenses/by/4.0), which permits unrestricted use, distribution, and reproduction in any medium, provided the original work is properly credited. The Creative Commons Public Domain Dedication waiver (http://creativecommons.org/publicdomain/zero/1.0/) applies to the data made available in this article, unless otherwise stated. 


\section{Background}

The prevalence of infection is high among patients admitted to ICUs and is one of the main causes of ICU mortality $[1,2]$. In 1992, a one-day European point-prevalence study on infections in intensive care (EPIC), performed in 1417 ICUs in 17 Western European countries [3], showed that approximately $45 \%$ of all patients present on the ICU on the study day were infected. The mean prevalence of ICUacquired infections was $21 \%$, but varied widely from $10 \%$ in Switzerland to $32 \%$ in Italy [3]. EPIC II was conducted 15 years later, on May 8, 2007 [2]. Data were collected from 13796 adult (>18 years) patients from 1265 ICUs in 75 countries and showed that $51 \%$ of patients had at least one infection.

Antimicrobial resistance is an increasing concern in ICUs worldwide. Rates of resistance vary considerably across different countries and regions; for example, ICUs in southern Europe generally have higher rates of resistance than countries in northern Europe and Scandinavia [4]. Several studies have reported that infection with an antibiotic resistant strain of an organism is associated with greater mortality and costs and longer ICU lengths of stay than infection with the non-resistant strain [5-9]. An important question is whether being admitted to an ICU with high levels of antimicrobial resistance is associated with a worse outcome than being admitted to an ICU with low rates of resistance, but there are few data available on this topic. In the present study, therefore, we used data from the large EPIC II study [2] to compare the characteristics of infections, antibiotic treatments and patient outcomes in patients admitted to ICUs in countries considered as having high levels of antibiotic resistance, as recorded in the Antimicrobial Resistance Surveillance System (EARSS) 2007 Annual Report, and those admitted to ICUs in countries considered as having low levels of antibiotic resistance. We hypothesized that there would be a difference in outcomes in patients admitted to ICUs in countries with high levels of antimicrobial resistance compared to those admitted to ICUs in countries with low levels of resistance.

\section{Methods}

The worldwide EPIC II 1-day point-prevalence study of infection and demographics of critically ill patients was performed on 8 May 2007 [2]. Data were collected for 13,796 adult patients in 1265 participating ICUs from 75 countries on the study day. Infection was defined according to the criteria of the International Sepsis Forum [10]. Microbiological analyses were performed locally. Participating ICUs were asked to provide patient followup until hospital discharge or for 60 days.

For the purposes of this analysis, we selected two groups of countries based on the country rate of methicillinresistant Staphylococcus aureus (MRSA) reported in the
European Antimicrobial Resistance Surveillance System (EARSS) 2007 Annual Report [11]: countries with MRSA rates of $\geq 25 \%$ in the 2007 report (Greece, Israel, Italy, Malta, Portugal, Spain, and Turkey) and countries with MRSA rates of $<5 \%$ (Denmark, Finland, Netherlands, Norway, and Sweden) (see Appendix for list of participating centres in these countries). Severity scores, source of infection, pathogens, antibiotic resistance, antibiotic therapy (prophylactic and therapeutic, as defined by the attending physician at each centre), co-morbidities, lengths of stay and outcomes were compared in patients in the two groups of countries.

The EPIC II study was approved by the ethics committee of Erasme Hospital, Belgium, the coordinating center. Local ethical committee approval at each participating center (see Appendix for list of participating centers) was expedited or waived because of the observational nature of the study.

\section{Statistical analyses}

Statistical analyses were performed using IBM SPSS Statistics 20 for Windows (IBM, Armonk, NY, USA). The Kolmogorov-Smirnov test was used, and histograms and Q-Q plots were examined to verify if there were significant deviations from the normality assumption of continuous variables. Difference testing between groups was performed using Mann-Whitney test, $\chi^{2}$ test, or Fisher's exact test as appropriate. Logistic regression analysis was used to determine the mortality risk associated with admission to an ICU in a country with high levels of antimicrobial resistance or one with low levels of antimicrobial resistance. To remove any bias of confounding variables for the association between the areas of ICU admission and mortality, a propensity score was estimated for each of the ICU areas, with the following variables considered as factors: type of admission, source of admission, comorbidities, age, sex, mechanical ventilation, haemofiltration or haemodialysis, infection, SAPS II score and type of microorganism. After checking that balance on all covariates that were used in the propensity model had been achieved, odds ratios with mortality as the dependent variable were estimated by logistic regression using two strategies: by matching and by introducing the propensity score in the model $[12,13]$. Reported odds ratios were adjusted for propensity score, hospital and organizational related factors, including type of ICU (closed vs. open, community vs. university, surgical vs. medical), number of ICU beds, number of nurses, number of physiotherapists, presence of 24-h ICU physician coverage, length of ICU stay prior to study day, percentage of gross domestic product spent on health care generated using the World Health Organization Statistical Information System (based on data from 2006 [14]) and geographical region. Data are presented as median [interquartile range (IQR)] or number (\%), as appropriate. 
Table 1 Characteristics of study population and participating units

\begin{tabular}{|c|c|c|c|c|}
\hline \multicolumn{2}{|l|}{ Characteristics } & LowABR countries & HighABR countries & p-value \\
\hline \multicolumn{2}{|l|}{ Of ICUs } & $\mathrm{N}=54$ & $\mathrm{~N}=231$ & \\
\hline \multicolumn{5}{|l|}{ Staffed ICU beds, n (\%) } \\
\hline \multicolumn{2}{|l|}{$<7$} & $14(25.9)$ & $67(29.0)$ & 0.9 \\
\hline \multicolumn{2}{|l|}{ 7-14 } & $30(55.6)$ & $122(52.8)$ & \\
\hline \multicolumn{2}{|l|}{$15+$} & $10(18.5)$ & $42(18.2)$ & \\
\hline \multicolumn{5}{|l|}{ Nurse:patient, n (\%) } \\
\hline \multicolumn{2}{|l|}{$>1: 1$} & $19(35.2)$ & $16(6.9)$ & $<0.001$ \\
\hline \multicolumn{2}{|l|}{ 1:1-1:1.49 } & $14(25.9)$ & $42(18.2)$ & \\
\hline \multicolumn{2}{|l|}{ 1:1.5-1:1.99 } & $18(33.3)$ & $78(33.8)$ & \\
\hline \multicolumn{2}{|l|}{$<1: 2$} & $3(5.6)$ & $95(41.1)$ & \\
\hline \multicolumn{2}{|l|}{ 24-hr in-house intensivist } & $48(88.9)$ & $231(100 \%)$ & $<0.001$ \\
\hline \multicolumn{2}{|l|}{ Of patients } & $N=558$ & $N=2204$ & \\
\hline \multicolumn{2}{|l|}{ Age, median (25-75 percentile) } & $65(53-74)$ & $65(51-74)$ & 0.574 \\
\hline \multicolumn{2}{|c|}{ SAPS II score, median (25-75 percentile) } & $31(25-39)$ & $34(26-44)$ & $<0.001$ \\
\hline \multicolumn{2}{|c|}{ SOFA score, median (25-75 percentile) } & $5(3-8)$ & $5(3-8)$ & 0.806 \\
\hline \multicolumn{2}{|c|}{ Length of stay in days in ICU prior to study day, median (25-75 percentile) } & $1(0-6)$ & $4(0-14)$ & $<0.001$ \\
\hline \multicolumn{2}{|l|}{ Infected } & $255(45.7)$ & $1187(53.9)$ & 0.001 \\
\hline \multirow[t]{4}{*}{ Type of admission, n (\%) } & Surgical, elective & $203(36.5)$ & $455(20.7)$ & $<0.001$ \\
\hline & Surgical, emergency & $200(36.0)$ & $952(43.2)$ & \\
\hline & Medical & $114(20.5)$ & $534(24.3)$ & \\
\hline & Trauma & $39(7.0)$ & $261(11.9)$ & \\
\hline \multirow[t]{5}{*}{ Admission source, $\mathrm{n}(\%)$} & OR/recovery & $205(37.7)$ & $472(21.5)$ & $<0.001$ \\
\hline & ED/ambulance & $111(20.4)$ & $680(31.0)$ & \\
\hline & Hospital ward & $160(29.4)$ & $713(32.5)$ & \\
\hline & Other hospital & $61(11.2)$ & $273(12.4)$ & \\
\hline & Other & $7(1.3)$ & $55(2.5)$ & \\
\hline \multirow[t]{8}{*}{ Main reason for admission, $\mathrm{n}(\%)$} & Surveillance/monitoring & $158(28.3)$ & $336(15.2)$ & $<0.001$ \\
\hline & Neurological & $56(10.0)$ & $350(15.9)$ & \\
\hline & Respiratory & $119(21.3)$ & $527(23.9)$ & \\
\hline & Cardiovascular & $119(21.3)$ & $579(26.3)$ & \\
\hline & Renal & $5(0.9)$ & $33(1.5)$ & \\
\hline & Digestive/liver & $53(9.5)$ & $154(7.0)$ & \\
\hline & Trauma & $36(6.5)$ & $198(9.0)$ & \\
\hline & Other & $12(2.2)$ & $27(1.2)$ & \\
\hline \multirow[t]{9}{*}{ Co-morbidities, n (\%) } & COPD & $77(13.8)$ & $457(20.7)$ & $<0.001$ \\
\hline & Haematological cancer & $11(2.0)$ & $49(2.2)$ & 0.715 \\
\hline & Cancer & $82(14.7)$ & $341(15.5)$ & 0.649 \\
\hline & IDDM & $42(7.5)$ & $221(10.0)$ & 0.072 \\
\hline & Heart Failure (NYHA III-IV) & $59(10.6)$ & $231(10.5)$ & 0.949 \\
\hline & $C R F$ & $14(2.5)$ & $165(7.5)$ & $<0.001$ \\
\hline & $H I V$ & $2(0.4)$ & $15(0.7)$ & 0.385 \\
\hline & Cirrhosis & $14(2.5)$ & $65(2.9)$ & 0.577 \\
\hline & Immunosuppression & $24(4.3)$ & $95(4.3)$ & 0.992 \\
\hline \multirow[t]{2}{*}{ Number of co-morbidities, n (\%) } & None & $282(50.5)$ & $1011(45.9)$ & 0.029 \\
\hline & 1 & 195 (34.9) & 746 (33.8) & \\
\hline
\end{tabular}


Table 1 Characteristics of study population and participating units (Continued)

\begin{tabular}{|c|c|c|c|c|}
\hline & 2 & $61(10.9)$ & $313(14.2)$ & \\
\hline & 3 & $16(2.9)$ & $103(4.7)$ & \\
\hline & $>3$ & $4(0.7)$ & $31(1.4)$ & \\
\hline \multirow[t]{2}{*}{ Treatments, n (\%) } & Mechanical ventilation & $359(64.7)$ & $1388(63.1)$ & 0.502 \\
\hline & Haemofiltration or haemodialysis & $47(8.5)$ & $171(7.8)$ & 0.591 \\
\hline \multirow[t]{2}{*}{ Length of stay, median (25-75 percentile) } & $\mathrm{ICU}$ & $5(1-19)$ & $12(3-31)$ & $<0.001$ \\
\hline & Hospital & $16(7-37)$ & $24(10-54)$ & $<0.001$ \\
\hline \multirow[t]{2}{*}{ Mortality } & $\mathrm{ICU}$ & $83(15.4)$ & $408(20.0)$ & 0.016 \\
\hline & Hospital & $116(21.5)$ & $551(27.0)$ & 0.01 \\
\hline
\end{tabular}

OR, operating room; ED, emergency department; COPD, chronic obstructive pulmonary disease; IDDM, insulin-dependent diabetes mellitus; NYHA III-IV, New York Heart Association class III-IV; CRF, chronic renal failure; HIV, human immunodeficiency virus.

All tests were two-tailed, and a $\mathrm{P}<0.05$ was considered statistically significant.

\section{Results}

In the EPIC II database, there were 2204 patients included from ICUs in countries with high levels of antimicrobial resistance (HighABR) according to the EARSS 2007 Annual Report [11] and 558 from ICUs in countries with low

Table 2 Microorganisms isolated from the 1048 culture-positive infected patients

\begin{tabular}{|c|c|c|c|}
\hline & $\begin{array}{l}\text { LowABR countries } \\
(n=196)\end{array}$ & $\begin{array}{l}\text { HighABR countries } \\
(\mathrm{n}=852)\end{array}$ & $\begin{array}{c}\mathrm{P}- \\
\text { value }\end{array}$ \\
\hline \multicolumn{4}{|l|}{ Pathogen, n (\%) } \\
\hline S. aureus & $32(16.3)$ & $137(16.1)$ & 0.993 \\
\hline MRSA & $2(1.0)$ & $69(8.1)$ & $<0.001$ \\
\hline MSSA & $30(15.3)$ & $70(8.2)$ & 0.002 \\
\hline S. epidermidis & $18(9.2)$ & $117(13.7)$ & 0.087 \\
\hline S. pneumoniae & $14(7.1)$ & $39(4.6)$ & 0.139 \\
\hline Enterococci & $31(15.8)$ & $92(10.8)$ & 0.049 \\
\hline $\mathrm{G}^{+}$, others & $20(10.2)$ & $48(5.6)$ & 0.019 \\
\hline E. coli & $36(18.4)$ & $128(15.0)$ & 0.245 \\
\hline Enterobacteriaceae & $10(5.1)$ & $52(6.1)$ & 0.592 \\
\hline Klebsiella & $21(10.7)$ & $92(10.8)$ & 0.973 \\
\hline P. aeruginosa & $27(13.8)$ & $172(20.2)$ & 0.039 \\
\hline Acinetobacter spp & $5(2.6)$ & $130(15.3)$ & $<0.001$ \\
\hline ESBL-producing & $4(2.0)$ & $10(1.2)$ & 0.340 \\
\hline $\mathrm{G}^{-}$, others & $37(18.9)$ & $136(16.0)$ & 0.322 \\
\hline Anaerobes & $15(7.7)$ & $22(2.6)$ & $<0.001$ \\
\hline Bacteria, others & $3(1.5)$ & $12(1.4)$ & 0.897 \\
\hline Candida & $45(23.0)$ & $156(18.3)$ & 0.136 \\
\hline Aspergillus & $1(0.5)$ & $8(0.9)$ & 0.557 \\
\hline Fungi, others & $5(2.6)$ & $6(0.7)$ & 0.022 \\
\hline Parasites & $4(2.0)$ & $6(0.7)$ & 0.083 \\
\hline Organisms, others & $12(6.1)$ & $19(2.2)$ & 0.004 \\
\hline
\end{tabular}

MRSA, methicillin-resistant S. aureus; MSSA, methicillin-sensitive S. aurues; $\mathrm{G}^{+}$, Gram positive; ESBL, extended-spectrum-beta-lactamase; G-, Gram negative. levels of antimicrobial resistance (LowABR) Table 1). The median SAPS II score was significantly higher in HighABR than in LowABR ICU patients (34 [26-44] vs 31 [25-39] $\mathrm{P}<0.001)$ and chronic renal failure and chronic obstructive pulmonary disease (COPD) were significantly more common (Table 1). Patients from HighABR ICUs were more often admitted from the emergency room and less often from the operating/recovery room than were patients from LowABR ICUs. Patients from HighABR ICUs had longer ICU and hospital lengths of stay than patients from LowABR ICUs; the number of days in the ICU prior to the study day was also longer in patients admitted to HighABR ICUs (Table 1).

\section{Infections and Microbiology}

More patients in the HighABR ICUs than in the LowABR ICUs were infected on the study day $(53.9 \%$ vs $45.7 \%, \mathrm{P}<0.01)$. The respiratory system was the most common site of infection in all patients (Additional file 1). The sites of infection were similar in the two groups except for abdominal infections, which were more common in patients admitted to LowABR ICUs $(24.3 \%$ vs $18.4 \%$, P $=0.03$ ), and bloodstream infections, which were more common in patients admitted to HighABR ICUs (19.6\% vs $16.1 \%, \mathrm{P}=0.03)$. Culture specimens were positive in 852 (71.8\%) of the patients from HighABR ICUs and in 196 (76.9\%) of the patients from LowABR ICUs $(\mathrm{P}=\mathrm{NS})$. As expected, MRSA was more common in patients in the HighABR ICUs than those in the LowABR ICUs $(69 / 137$ [50\%] vs $2 / 32$ [6\%], $\mathrm{P}<0.001$ ) (Table 2). Infections caused by Pseudomonas aeruginosa or Actinetobacter were significantly more prevalent among HighABR ICU patients (Table 2), whereas methicillin-sensitive $S$. aureus (MSSA), enterococci and anaerobes were more common in LowABR ICU patients.

\section{Antibiotic use Treatment}

Use of therapeutic antimicrobials was significantly more common overall in HighABR ICU patients than in 
Table 3 Use of antimicrobials as treatment in infected patients

\begin{tabular}{|c|c|c|c|}
\hline & $\begin{array}{l}\text { LowABR ICU } \\
\text { patients } \\
(n=255)\end{array}$ & $\begin{array}{l}\text { HighABR ICU } \\
\text { patients } \\
(n=1187)\end{array}$ & $p$-value \\
\hline \multicolumn{4}{|l|}{ Antimicrobial, n (\%) } \\
\hline Cephalosporins (all) & $84(32.9)$ & $206(17.4)$ & $<0.001$ \\
\hline Cefazolin & $4(1.6)$ & $4(0.3)$ & 0.016 \\
\hline Cefuroxime & $46(18.0)$ & $2(0.2)$ & $<0.001$ \\
\hline Ceftazidime & $8(3.1)$ & $40(3.4)$ & 0.851 \\
\hline Cefepime/Cefpirome & $1(0.4)$ & $24(2.0)$ & 0.070 \\
\hline Other cephalosporins & $26(10.2)$ & $139(11.7)$ & 0.491 \\
\hline Penicillins (all) & $84(32.9)$ & $400(33.7)$ & 0.816 \\
\hline Benzylpenicillin & $16(6.3)$ & $3(0.3)$ & $<0.001$ \\
\hline Ampicillin & $5(2.0)$ & $29(2.4)$ & 0.645 \\
\hline $\begin{array}{l}\text { Amoxycillin }+ \\
\text { Clavulanic acid }\end{array}$ & $16(6.3)$ & $71(6.0)$ & 0.858 \\
\hline $\begin{array}{l}\text { Piperacillin + } \\
\text { Tazobactam }\end{array}$ & $27(10.6)$ & $273(23.0)$ & $<0.001$ \\
\hline $\begin{array}{l}\text { Oxa-/Cloxa-/ } \\
\text { Flucloxacillin }\end{array}$ & $14(5.5)$ & $16(1.3)$ & $<0.001$ \\
\hline Other penicillins & $8(3.1)$ & $20(1.7)$ & 0.127 \\
\hline Other $\beta$-lactams (all) & $44(17.3)$ & $381(32.1)$ & $<0.001$ \\
\hline $\begin{array}{l}\text { Imipenem/ } \\
\text { meropenem }\end{array}$ & $44(17.3)$ & $365(30.7)$ & $<0.001$ \\
\hline Aztreonam & $0(0.0)$ & $13(1.1)$ & 0.093 \\
\hline $\begin{array}{l}\text { Unspecified } \\
\text { beta-lactams }\end{array}$ & $0(0.0)$ & $7(0.6)$ & 0.219 \\
\hline Aminoglycosides (all) & $17(6.7)$ & $202(17.0)$ & $<0.001$ \\
\hline Amikacin & $0(0.0)$ & $114(9.6)$ & $<0.001$ \\
\hline Tobramycin & $11(4.3)$ & $26(2.2)$ & 0.052 \\
\hline $\begin{array}{l}\text { Other } \\
\text { aminoglycosides }\end{array}$ & $6(2.4)$ & $66(5.6)$ & $<0.001$ \\
\hline Quinolones (all) & $38(14.9)$ & $242(20.4)$ & 0.045 \\
\hline Ciprofloxacin & $31(12.2)$ & $128(10.8)$ & 0.525 \\
\hline Other quinolones & $7(2.7)$ & $114(9.7)$ & $<0.001$ \\
\hline Glycopeptides (all) & $30(11.8)$ & $272(22.9)$ & $<0.001$ \\
\hline Vancomycin & $30(11.8)$ & $193(16.3)$ & 0.072 \\
\hline Other glycopeptides & $0(0.0)$ & $81(6.8)$ & $<0.001$ \\
\hline Macrolides (all) & $13(5.1)$ & $48(4.0)$ & 0.448 \\
\hline Erythromycin & $6(2.4)$ & $4(0.3)$ & $<0.001$ \\
\hline Other macrolides & $7(2.7)$ & $44(3.7)$ & 0.451 \\
\hline Other antibiotics (all) & $55(21.6)$ & $321(27.0)$ & 0.071 \\
\hline Metronidazole & $36(14.1)$ & $71(6.0)$ & $<0.001$ \\
\hline Cotrimoxazole & $5(2.0)$ & $30(2.5)$ & 0.594 \\
\hline Oxazolidinone & $0(0.0)$ & $128(10.8)$ & $<0.001$ \\
\hline Tigecycline & $0(0.0)$ & $21(1.8)$ & 0.032 \\
\hline Unspecified & $19(7.5)$ & $130(11.0)$ & 0.096 \\
\hline Antifungals (all) & $52(20.4)$ & 209 (17.6) & 0.295 \\
\hline
\end{tabular}

Table 3 Use of antimicrobials as treatment in infected patients (Continued)

\begin{tabular}{lccc}
\hline Fluconazole & $31(12.2)$ & $110(9.3)$ & 0.159 \\
Amphotericin B & $4(1.6)$ & $18(1.5)$ & 0.951 \\
$\begin{array}{l}\text { Amphotericin lipid } \\
\text { complex }\end{array}$ & $3(1.2)$ & $21(1.8)$ & 0.502 \\
Caspofungin & $12(4.7)$ & $40(3.4)$ & 0.299 \\
Voriconazole & $1(0.4)$ & $31(2.6)$ & 0.029 \\
Other antifungals & $1(0.4)$ & $2(0.2)$ & 0.477 \\
Antivirals (all) & $3(1.2)$ & $22(1.9)$ & 0.452 \\
\hline
\end{tabular}

LowABR ICU patients ( $54.6 \%$ vs $44.4 \%, \mathrm{P}<0.001)$. When considering groups of antimicrobials, carbapenems, aminoglycosides, quinolones and glycopeptides were more commonly used in patients in HighABR ICUs than in LowABR ICUs, whereas cephalosporins were used more frequently as treatment in LowABR ICUs (Table 3). For individual antimicrobials, piperacillin-tazobactam, imipenem/meropenem, amikacin, oxazolidinone and tigecycline were used more frequently in patients in HighABR ICUs; cefazolin, cefuroxime, benzylpenicillin, oxa-/cloxa-/flucloxacillin, erythromycin and metronidazole were used more frequently in patients in LowABR ICUs (Table 3).

\section{Prophylaxis}

Use of prophylactic antimicrobials was significantly less common in HighABR ICU patients than in LowABR ICU patients $(22.2 \%$ vs $32.8 \%, \mathrm{P}<0.001)$. Among the agents most commonly used were aminoglycosides (tobramycin), antifungals (amphotericin B) and cephalosporins (Additional file 2).

\section{Mortality}

Crude ICU (20.0\% and 15.4\%) and hospital (27.0\% vs $21.5 \%)$ mortality rates were higher in patients admitted to HighABR than in those admitted to LowABR ICUs (both $\mathrm{P}<0.05$ ); however, these differences were not present after adjustment in multivariable analysis or the matched pair analysis (Table 4). For subgroups of infected or non-infected patients there were no significant differences in crude or adjusted mortality rates between HighABR and LowABR ICUs.

Patients with infections due to Pseudomonas aeruginosa had crude ICU and hospital mortality rates of $32.4 \%$ and $42.7 \%$, respectively. Corresponding percentages for patients with Acinetobacter infections were 31.7 and 37.3, respectively, and for MRSA 32.3 and 43.1, respectively. Because of the relatively small sample sizes, we were unable to compare outcomes for the different pathogens in the two groups. 
Table 4 Crude and adjusted odds ratios* $(95 \% \mathrm{CI})$ for ICU and hospital mortality in the whole cohort and in infected patients

\begin{tabular}{lcccccc}
\hline & OR (95\% Cl) & P-value & m-OR (95\% Cl) & P-value & a-OR (95\% Cl) & P-value \\
\hline ICU mortality (all) & $1.37(1.06-1.78)$ & 0.016 & $1.14(0.76-1.73)$ & 0.526 & $1.07(0.78-1.48)$ & 0.661 \\
Hospital mortality (all) & $1.35(1.07-1.69)$ & 0.01 & $1.07(0.74-1.55)$ & 0.707 & $1.12(0.84-1.48)$ & 0.445 \\
ICU mortality (infected) & $1.23(0.88-1.72)$ & 0.222 & $1.23(0.73-2.09)$ & 0.438 & $0.99(0.66-1.49)$ & 0.95 \\
Hospital mortality (infected) & $1.21(0.89-1.63)$ & 0.218 & $1.02(0.63-1.65)$ & 0.933 & $1.1(0.77-1.58)$ & 0.606 \\
ICU mortality (not infected) & $1.38(0.91-2.09)$ & 0.131 & $1.01(0.5-2.02)$ & 0.984 & $1.32(0.78-2.22)$ & 0.304 \\
Hospital mortality (not infected) & $1.33(0.93-1.92)$ & 0.121 & $1.16(0.64-2.11)$ & 0.629 & $1.19(0.75-1.9)$ & 0.461 \\
\hline
\end{tabular}

OR: Odds ratio; m-OR: Odds ratio from matched-pairs. a-OR: adjusted odds ratio. *With admission to HighABR ICU as the reference category. The list of confounders included in the multivariable analysis is reported in the text.

\section{Discussion}

The main message of this study is that hospitalization in an ICU in a country with high levels of antimicrobial resistance is not an independent risk factor for worse outcome. We chose to select countries with likely high and low antimicrobial resistance using reported MRSA rates, although acknowledge that general resistance rates may have been different; nevertheless, most countries with high MRSA rates do seem to have high resistance levels among other organisms [11]. Several studies have shown increased mortality rates in patients with MRSA infections compared to those with MSSA infections $[15,16]$. In an earlier analysis of the EPIC II database, MRSA infection was associated with an increased risk of death compared to MSSA infection (OR 1.46 [95\% CI 1.03-2.06], $\mathrm{P}=0.03$ ) [17]. Using data from the European Antimicrobial Resistance Surveillance System and the Burden of Resistance and Disease in European Nations project, De Kraker et al. [15] reported that 27,711 episodes of MRSA blood stream infections (BSIs) were associated with 5,503 excess deaths. The same authors compared two prospective cohorts of patients from 13 ICUs in 13 European countries, one with MRSA and one with MSSA BSIs, each matched with control patients without the respective BSI [16]. MRSA and MSSA patients had higher 30-day and hospital mortality than the control patients, and MRSA patients had greater 30-day mortality (OR 1.8, $\mathrm{P}=0.04$ ) than MSSA patients. Other studies have reported similar mortality rates in MRSA and MSSA patients, but longer lengths of stays and higher associated costs $[6,7,18]$.

Infections due to difficult to treat pathogens, i.e., $P$. aeruginosa, Acinetobacter spp and MRSA, were in general associated with higher crude ICU and hospital mortality rates in our study than other infections and were significantly more prevalent in HighABR ICUs; however, because of small sample sizes, comparisons between groups were not possible. We know from other ICU studies that these pathogens are associated with increased attributable mortality if empirical treatment is not appropriate [19-21]. Unfortunately, we are unable to determine whether or not treatment was appropriate in our study, although we did show that broadspectrum antibiotics, such as carbapenems, piperacillin-tazobactam, amikacin, tigecycline, oxazolidinone and vancomycin, were more commonly used for treatment in the HighABR ICUs. Similarly, we did not record antibiograms for the different species and have no data on rates of resistance, except for S. aureus and ESBL-producing Gram-negative bacteria. Infections caused by enterococci and anaerobes were more common in LowABR ICU patients which may explain the more frequent abdominal infections and use of metronidazole in these ICUs.

\section{Conclusions}

Infections were more prevalent among patients admitted to ICUs in HighABR countries than in LowABR countries. Antibiotic therapy differed markedly, with broader spectrum antimicrobials being used more frequently in HighABR countries. ICU patients in HighABR countries were sicker and had longer ICU and hospital stays and higher crude ICU and hospital mortality rates, which could have a marked economical impact; however, after multivariate adjustment there were no differences in ICU or hospital mortality rates between the two groups of patients.

\section{Appendix: List of participating centres for this EPIC II substudy by country, alphabetically}

Denmark: Århus University Hospital (H Betsch); Næstved Hospital (B Fogh); Rigshospitalet (K Espersen); Sygehus Fyn (K Jacobsen); Vejle Sygehus (P Berezowicz); Finland: Helsinki University Central Hospital (V Harjola); Greece: Ahepa University Hospital (E Sofianos); Athens University Medical School (A Armaganidis); Evangelismos Hospital (C Routsi); G.Papanikolaou (M Bitzani); General Hospital of Rethymno (A Chalkiadaki); Henry Dunant Hospital (A Michalopoulos); Hippokrateion Hospital Thessaloniki (E Mouloudi); Kat General Hospital (E Ioannidou); Kat 
Hospital (P Myrianthefs); Kat Hospital, Athens (D Koulenti); Konstantopoulio General Hospital (I Karampela); Lamia General Hospital (G Kyriazopoulos); Red Cross Hospital of Athens ( $\mathrm{K}$ Mandragos); Thriassio Hospital of Eleusis (P Clouva-molyvdas); University Hospital of Ioannina (A Moraiti); University Hospital of Alexandroupolis (I Pneumatikos); University Hospital of Rion, Patras (K Filos); University Hospital of Thessaly (Larissa) (E Zakynthinos); University of Athens, Medical Shcool (A Kotanidou); Xanthi General Hospital (A Vakalos); Israel: Hadassah Medical Center (C Sprung); Haemek Medical Center (A Lev); Kaplan Medical Center (E Kishinevsky); Rabin Medical Center (J Cohen); Soroka Medical Center (S Sofer) Italy: A.O Niguarda (S Vesconi); A.O. Ospedale Di Circolo Di Busto Arsizio (S Greco); A.O. Treviglio-Caravaggio (M Borelli); Anestesia E Rianimazione 2 Prof.De Gaudio (P Cecilia); Arnas Ospedale Civico (M Sapuppo); ASL 10 (A Lazzero); ASL 10 Florence Hospital San Giovanni Di Dio (V Mangani); Azienda Ospedaliera Desenzano (N Petrucci); Azienda Ospedaliera Di Melegnano (M Minerva); Azienda Ospedaliera G. Rummo (E De blasio); Azienda Ospedaliera Polo Universitario San Paolo (S Marzorati); Azienda Ospedaliera Santa Maria Alle Scotte (R Rosi); Azienda Ospedaliera Universitaria P.Giaccone Policlinico (A Giarratano); Azienda Ospedaliera-Universitaria Udine (O Margarit); Azienda Ospedaliero -Universitaria (A Guberti); Azienda Ospedaliero-Universitaria S.M.Misericordia (S Scolz); Clinica San Gaudenzio (E Stelian); Fondazione IRCCS Policlinico San Matteo (V Emmi); Fondazione Ospedale Maggiore Policlinico, Mangiagalli Regina Elena (M Caspani); Fondazione Poliambulanza (A Rosano); H San Gerardo (C Abbruzzese); Hospital Panico Tricase (S Colonna); Humanitas Gavazzeni (R Ceriani); II Faculty of Medicne I University of Rome- Osp. S.Andrea (R De Blasi); S. Salvatore Hospital (L Panella); IRCCS Casa Sollievo Della Sofferenza (F Borrelli); Istituto Nazionale Tumori Regina Elena (P Lorella); KH Brixen (H Ruatti); Osepdali Riuniti Di Ancona (C Munch); Ospedale "Ca Foncello" - Treviso (Italia) (C Sorbara); Ospedale "Santa Croce" - ASL 8 (G Fiore); Ospedale Bufalini-Cesena (A Chieregato); Ospedale Di Circolo E Fondazione Macchi (V Conti); Ospedale Di Massa (A Guadagnucci); Azienda USL Piacenza (M Pizzamiglio); Ospedale Ferrarotto (M Locicero); Ospedale Maggiore Ausl Bologna (I Marri); Ospedale Maggiore Policlinico Milano (A Sicignano); Ospedale Maggiore Policlinico, Mangiagalli E Regina Elena, IRCCS Milano (V Conte); Ospedale Mugello Azienda Sanitaria Firenze (R Oggioni); Ospedale Niguarda Ca Granda, Milano (A De Gasperi); IRCCS Centro di Riferimento Oncologico della Basilicata (P De Negri); Ospedale Provinciale Pistoia (G Santagostino); Ospedale S. Gerardo (R Fumagalli); Ospedale San Raffaele (G Marino); Ospedele Vittorio Emanuele (G Castiglione); P.O. San Severo Asl Fg
(D Sforza); S. Camillo Hospitql (N Giuseppe); San Martino Hospital (M Bassetti); Seconda Università Degli Studi Di Napoli (F Ferraro); Sesto San Giovanni Hospital (S Clementi); Teaching Hospital Careggi (D Alessandro); Terapia Intensiva - Aso S. Giovanni Battista Di Torino - Ospedale Molinette (P Cotogni, MV Ranieri); Università Cattolica ( $\mathrm{M}$ Antonelli); Universita' Cattolica Del S. Cuore (L Martinelli); University-Hospital Careggi, Florence, (L Gianesello); University Hospital Policlinico Di Catania (A Gullo); University of Rome "La Sapienza" (A Morelli); UTI Trapianti (G Biancofiore); University of Udine (G Della Rocca) Malta: St Luke's Hospital (M Borg); Netherlands: Academic Medical Center (A De Pont); Amphia Hospital (P Rosseel); Antoni Van Leeuwenhoek Ziekenhuis (J Ten Cate); Beatrix Zienhuis Rivas Zorggroep (G Van Berkel); Canisius Wilhelmina Ziekenhuis (S Corsten); Erasmus Mc University Medical Center (J Bakker); Hagaziekenhuis (J Vogelaar); Hofpoort Hospital Woerden (H Blom); Isala Clinics (H Kieft); Medical Center Leeuwarden (M Kuiper); Medisch Spectrum Twente (A Gille); Radboud University Nijmegen Medical Centre (P Pickkers); Rode Kruis Ziekenhuis (J Vet); Slingeland Ziekenhuis (J Ammann); Spaarneziekenhuis (S Den Boer); St. Antonius Ziekenhuis (R Wesselink); St.Elisabeth Hospital (B Speelberg); Twenteborg Hospital Almelo (C Pham); University Medical Center, Groningen (M Rodgers); University Hospital Maastricht (D Bergmans); Vu University Medical Center (J Groeneveld); Norway: Aker University Hospital (R Loevstad); St Olavs University Hospital (P Klepstad); Sykehuset Asker Og Bærum Hf (P Erno); Sykehuset I Vestfold Hf, Toensberg (A Junker); Portugal: Centro Hospitalar Alto Ave (A Bártolo); Centro Hospitalar Cova Da Beira (M Castelo-Branco Sousa); Centro Hospitalar Trás os Montes e Alto Douro (F Esteves); CHLO-Hospital S Francisco Xavier (A Martins); H S João (T Oliveira); Hospital CUF Infante Santo (P Ponce); Hospital Curry Cabral (L Mourão); Hospital da Luz (C Febra); Hospital de Egas Moniz (E Carmo); Hospital de S. José (V Lopes); Hospital de São Francisco Xavier (P Póvoa); Hospital de São José (A Rezende); Hospital Divino Espirito Santo (H Costa); Hospital do Litoral Alentejano (P Moreira); Hospital Dr. José Maria Grande, Portalegre (F Pádua); Hospital Fernando Fonseca (A Leite); Hospital Garcia de Orta (E Almeida); Hospital Geral de Santo António (M Alves); Hospital de Pulido Valente (A Sousa, L Telo); Hospital de S. João (C Dias, J Paiva); Hospital de São Bernardo (R Ribeiro); Hospital de São Sebastião, EPE (P Amaro); Hospital Geral de Sto Antánio (A Carneiro); Hospital de St. António dos Capuchos (R Moreno, Ricardo Matos, Susana Afonso); Instituto Português de Oncologia de Lisboa (M Bouw); Hospital de St Maria (C França); Spain: Althaia (O Rubio); Bellvitge University Hospital (R Mañez); Centro Medico Delfos (M Burgueño Campiñez); Clinica Moncloa (M 
Alvarez); Clinica Rotger (R Jorda); Clinica Santa Elena (E Naveira-Abeigón); Clinica Universitaria de Navarra (P Monedero); Complejo Hospitalario de Pontevedra (E Alemparte-Pardavila); Fundacion Hospital Alcorcon (S Garcia del Valle); Fundacion Jimenez Diaz (C Perez Calvo); H Vall Hebron (M Palomar); H.U. Virgen de Las Nieves- H. Traumatología Y Rehabilitación (F Guerrero); Hospital "Virgen de La Concha" - Zamora (A Caballero Zirena); Hospital Arnau de Vilanova (M Arribas); Hospital Can Misses (E Bustamante Munguira); Hospital Casa de Salud (J Ruiz); Hospital Central de Asturias (L Iglesias); Hospital Clinic (E Zavala); Hospital Clinic de Barcelona (M Valencia); Hospital Clinico San Carlos (A Blesa Malpica); Hospital Clinico San Carlos (F Martinez-Sagasti, M Nieto); Hospital Clinico Universitario (G Aguilar); Hospital Clinico Universitario de Santiago (F Martinon-Torres); Hospital Comarcal Vinaros (C Lorente); Hospital de Navarra (J Insausti); Hospital de Antequera (R Vegas Pinto); Hospital de Basurto (I Santos); Hospital de Fuenlabrada (A Escriba); Hospital de Galdakao (P Olaechea); Hospital de La Merced (E Muñoz); Hospital de Manacor (E Antón Caraballo); Hospital de Mostoles (P Galdos-Anuncibay); Hospital de Sagunto (V Lopez Camps); Hospital de Tortosa Verge de La Cinta (F Esteban-Reboll); Hospital del Sas de Jerez (A Estella); Hospital Donostia (L Bocero); Hospital Dr Peset (A Ibañez); Hospital G. Yagüe (L Pueyo); Hospital General (L María Jesús); Hospital General de Asturias (L Iglesias); Hospital General de Ciudad Real (J Silva); Hospital General de Granollers (P Garro); Hospital General de La Palma (L Ramos-gómez); Hospital General de L'Hospitalet (A Rovira); Hospital General de Vic (M Martin Delgado); Hospital General Salud "Obispo Polanco" (J Monton Dito); Hospital General Universitario de Albacete (F Garcia); Hospital General Universitario de Alicante (J Navarro); Hospital General Universitario de Elche (J Latour-Perez); Hospital General Universitario de Guadalajara (A Albaya); Hospital General Universitario Gregorio Marañon (A Bustinza); Hospital Gran Canaria "Dr Negrín" (J Sole-violán); Hospital Marques de Valdecilla (P Ugarte Peña); Hospital Maz (I Yuste); Hospital Parque San Antonio (J De Rojas Román); Hospital Sabadell (J Vallés); Hospital Sant Joan de Déu (E Esteban); Hospital Sant Pau (E Quintana Tort-Martorell); Hospital Santa María del Rosell (M Moreno); Hospital Santa Maria Madre-Complejo Hospitalario de Ourense (V López Ciudad); Hospital Santiago Apostol (A Manzano Ramirez); Hospital Sevilla-Aljarafe (J Sánchez-Olmedo); Hospital Son Llàtzer (M Borges); Hospital Terrassa (J Amador Amerigo); Hospital Torrecardenas (F Guerrero Gomez); Hospital Universitaio 12 de Octubre (J Montejo González); Hospital Universitari de Girona Doctor Josep Trueta (J Sirvent); Hospital Universitari Germans Trias I Pujol (E Mesalles Sanjuan); Hospital Universitario Arnau de Vilanova (F Barcenilla-Gaite); Hospital Universitario de Canarias (N Serrano); Hospital Universitario de Getafe (E Cerdá);
Hospital Universitario de Valme (A Lesmes Serrano); Hospital Universitario Doce de Octubre (C GarciaFuentes); Hospital Universitario Infanta Crsitina (J Macias Pingarrón); Hospital Universitario $\mathrm{N}^{\mathrm{a}}$ sra de Candelaria (E Espinosa); Hospital Universitario Principe de Asturias (M Sanchez Garcia); Hospital Universitario Reina Sofía, Murcia (F Felices); Hospital Universitario Virgen de La Victoria (M de la Torre-Prados); Hospital Univesitario Puerto Real $(\mathrm{H}$ Maria Jesus); Hospital Valle del Nalon (V Luis); Hospital Virgen Arrixaca ( $\mathrm{R}$ Jara); Hospital Xanit Internacional (M Briones Lopez); Hospital Xeral Cies (P Posada); Hu La Paz (B Galvan); Hu La Paz (F Mariscal); Joan Xxiii University Hospital (J Rello); Morales Meseguer (B Gil); Puerta del Mar Universitary Hospital (R Sierra); Rio Hortega University Hospital (J Rico-Feijoo); San Pedro de Alcantara Hospital (C Corcobado Márquez); Servicio Navarro de Salud.Hospital Virgen del Camino (J Izura); Uci H. U. Salamanca (J González); Universitary Hospital Dr. Peset (J Soto Ibáñez); Sweden: Anestesikliniken (P Petersen); Centralsjukhuset Karlstad (L Johansson); University Hospital, Linköping ( $\mathrm{H}$ Blomqvist, B Peterzén, N Wyon); Göteborg (I Lindström); Kärnsjukhuset Skövde (A Paulsson); Karolinska University Hospital Huddinge (C Agvald-Ohman); Karolinska University Hospital, Solna (J Petersson); Lund University Hospital (H Friberg); Malmoe University Hospital (V Einar); Op/Iva Kliniken (F Hammarskjöld); Ostersund Hospital (M Schindele); Ostra Hospital, Göteborg (S Arvidsson); Sahlgrenska University Hospital (J Sellgren); Söder Hospital (Södersjukhuset) (J Hulting); Sodersjukhuset (J Häggqvist); Sollefteå Hospital (J Rudenstam); Sunderby Hospital (D Lind); The Queen Silvia Children's Hospital (E Kokinsky); Thoracic Intensive Care, Karolinska Hospital (A Owall); Umeå University Hospital (S Jacobson); University Hospital (H Stiernstrom); University Hospital of Örebro (A Nydahl); Turkey: Acibadem Kadikoy Hospital (K Atalan); Acibadem Bakirkoy Hospital (C Ates); Acibadem Bursa Hospital (A Kahveci); Acibadem Kozyatagi Hospital (H Fistikci); Ankara Univercity (A Kaya); Ankara University Medical Faculty, Ibni Sina Hospital (E Ozgencil); Ataturk University Medical Faculty (M Kizilkaya); Dicle University Medical School (M Bosnak); Dokuz Eylul University (H Bodur); Dokuz Eylul University School of Medicine (M Akan); Erciyes University Medical Faculty (M Guven); Gazi University School of Medicine (M Turkoglu); Hacettepe University Hospital (A Topeli); Inonu University Medical Faculty ( $\mathrm{T}$ Togal); Istanbul Faculty of Medicine (N Uzel); Istanbul Medical Faculty (I Akinci, N Cakar, S Tugrul); Istanbul University Cerrahpasa Medical School (O Demirkiran); Izmir Ataturk Training and Resarch Hospital (T Adanir); Memorial Hospital (K Dogruer); Okmeydani Teaching \& Research Hospital (A Turkmen); Okmeydani Teaching \& Research Hospital (H Guven); Ondokuz Mayis University, Medical Faculty (F Ulger); Selcuk University Meram Faculty of Medicine (S Kocak). 


\section{Additional files}

\section{Additional file 1: Sites of infection. \\ Additional file 2: Use of antimicrobials as prophylaxis in all patients.}

\section{Competing interests}

The authors declare that they have no conflicts of interests related to this manuscript.

\section{Authors' contributions}

$\mathrm{HH}$ conceived the study, contributed to data analysis and interpretation, drafted and revised the article, and read and approved the final version. MA contributed to data acquisition, critically revised the article, and read and approved the final version. $\mathrm{MH}$ contributed to data analysis and interpretation, drafted the article, and read and approved the final version. JL contributed to data acquisition, critically revised the article, and read and approved the final version. PP contributed to data acquisition, critically revised the article, and read and approved the final version. ML contributed to data acquisition, critically revised the article, and read and approved the final version. JR contributed to data acquisition, critically revised the article, and read and approved the final version. YS contributed to data acquisition, critically revised the article, and read and approved the final version. SMW contributed to data acquisition, data analysis and interpretation, drafted the article, and read and approved the final version. PV contributed to data acquisition, critically revised the article, and read and approved the final version. JLV helped conceive the study, contributed to data interpretation, critically revised the article, and read and approved the final version.

\section{Acknowledgments}

We would like to thank Hassane Njimi, MSc, PhD, Department of Intensive Care, Erasme University Hospital, Brussels, Belgium, for his statistical support.

\section{Author details}

${ }^{1}$ Division of Infectious Diseases, Institution of Clinical and Experimental Medicine, Faculty of Health Sciences, Linköping University, Linköping, Sweden. ¿Università Cattolica del Sacro Cuore - Policlinico Universitario A. Gemelli, Rome, Italy. ${ }^{3}$ Department of Intensive Care Medicine, Royal Brisbane and Women's Hospital, The University of Queensland, Herston, QLD, Australia. ${ }^{4}$ Department of Intensive Care Medicine, Radboud University Medical Centre, Nijmegen, The Netherlands. ${ }^{5}$ Department of Intensive Care and Anesthesiology, Hôpital Nord, AP-HM Unité de Recherche en Maladies Infectieuses et Transmissibles (URMITE), Aix-Marseille University, Marseilles, France. ${ }^{6}$ Critical Care Department, Vall d'Hebron University Hospital, CIBERES, VHIR, Universitat Autonoma de Barcelona, Barcelona, Spain. ${ }^{7}$ Department of Anesthesiology and Intensive Care,

Friedrich-Schiller University, Jena, Germany. ${ }^{8}$ Division of Cardiovascular Medicine, Department of Medicine and Health, Faculty of Health Sciences, Linköping University, Linköping, Sweden. 'SService d'Hygiène, Epidémiologie et Prévention, Groupement Hospitalier Edouard Herriot, Hospices Civils de Lyon, Université Lyon 1, Lyon, France. ${ }^{10}$ Department of Intensive Care, Erasme Hospital, Université Libre de Bruxelles, Brussels, Belgium.

Received: 3 July 2014 Accepted: 11 September 2014 Published: 22 September 2014

\section{References}

1. Vincent JL, Sakr Y, Sprung CL, Ranieri VM, Reinhart K, Gerlach H, Moreno R, Carlet J, Le Gall JR, Payen D: Sepsis in European intensive care units: results of the SOAP study. Crit Care Med 2006, 34:344-353.

2. Vincent JL, Rello J, Marshall J, Silva E, Anzueto A, Martin CD, Moreno R, Lipman J, Gomersall C, Sakr Y, Reinhart K: International study of the prevalence and outcomes of infection in intensive care units. JAMA 2009, 302:2323-2329.

3. Vincent JL, Bihari DJ, Suter PM, Bruining HA, White J, Nicolas-Chanoin MH, Wolff M, Spencer RC, Hemmer M: The prevalence of nosocomial infection in intensive care units in Europe. Results of the European Prevalence of Infection in Intensive Care (EPIC) Study. EPIC International Advisory Committee. JAMA 1995, 274:639-644.

4. European Center for Disease Prevention and Control: Antimicrobial resistance surveillance in Europe 2011. Annual Report of the European Antimicrobial
Resistance Surveillance Network (EARS-Net). [http://www.ecdc.europa.eu/en/ publications/publications/antimicrobial-resistance-surveillance-europe-2011.pdf]

5. Cosgrove SE: The relationship between antimicrobial resistance and patient outcomes: mortality, length of hospital stay, and health care costs. Clin Infect Dis 2006, 42(Suppl 2):S82-S89.

6. Macedo-Vinas M, De Angelis G, Rohner P, Safran E, Stewardson A Fankhauser C, Schrenzel J, Pittet D, Harbarth S: Burden of meticillinresistant Staphylococcus aureus infections at a Swiss University hospital: excess length of stay and costs. J Hosp Infect 2013, 84:132-137.

7. Rubio-Terres C, Garau J, Grau S, Martinez-Martinez L: Cost of bacteraemia caused by methicillin-resistant vs. methicillin-susceptible Staphylococcus aureus in Spain: a retrospective cohort study. Clin Microbiol Infect 2010, 16:722-728.

8. Patel G, Huprikar S, Factor SH, Jenkins SG, Calfee DP: Outcomes of carbapenem-resistant Klebsiella pneumoniae infection and the impact of antimicrobial and adjunctive therapies. Infect Control Hosp Epidemiol 2008, 29:1099-1106.

9. Salgado CD, Farr BM: Outcomes associated with vancomycin-resistant enterococci: a meta-analysis. Infect Control Hosp Epidemiol 2003, 24:690-698.

10. Calandra T, Cohen J: The international sepsis forum consensus conference on definitions of infection in the intensive care unit. Crit Care Med 2005, 33:1538-1548.

11. European Antimicrobial Resistance Surveillance System: The European Antimicrobial Resistance Surveillance System (EARSS) Annual Report 2007. [http://www.ecdc.europa.eu/en/activities/surveillance/EARS-Net/Documents/ 2007_EARSS_Annual_Report.pdf]

12. Rubin DB: Estimating causal effects from large data sets using propensity scores. Ann Intern Med 1997, 127:757-763.

13. Rubin DB: For objective causal inference, design trumps analysis. Ann App/ Stat 2008, 2:808-840.

14. World Health Organization: World Health Statistics 2006. http://www.who.int/ whosis/whostat2006.pdf.

15. de Kraker ME, Davey PG, Grundmann H: Mortality and hospital stay associated with resistant Staphylococcus aureus and Escherichia coli bacteremia: estimating the burden of antibiotic resistance in Europe. PLoS Med 2011, 8:e1001104.

16. de Kraker ME, Wolkewitz M, Davey PG, Koller W, Berger J, Nagler J, Icket C, Kalenic S, Horvatic J, Seifert H, Kaasch AJ, Paniara O, Argyropoulou A, Bompola M, Smyth E, Skally M, Raglio A, Dumpis U, Kelmere AM, Borg M, Xuereb D, Ghita MC, Noble M, Kolman J, Grabljevec S, Turner D, Lansbury L, Grundmann H: Clinical impact of antimicrobial resistance in European hospitals: excess mortality and length of hospital stay related to methicillin-resistant Staphylococcus aureus bloodstream infections. Antimicrob Agents Chemother 2011, 55:1598-1605.

17. Hanberger H, Walther S, Leone M, Barie PS, Rello J, Lipman J, Marshall JC, Anzueto A, Sakr Y, Pickkers P, Felleiter P, Engoren M, Vincent JL: Increased mortality associated with methicillin-resistant Staphylococcus aureus (MRSA) infection in the intensive care unit: results from the EPIC II study. Int J Antimicrob Agents 2011, 38:331-335.

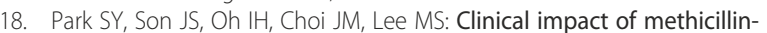
resistant Staphylococcus aureus bacteremia based on propensity scores. Infection 2011, 39:141-147.

19. Lodise TP Jr, Patel N, Kwa A, Graves J, Furuno JP, Graffunder E, Lomaestro B, McGregor JC: Predictors of 30-day mortality among patients with Pseudomonas aeruginosa bloodstream infections: impact of delayed appropriate antibiotic selection. Antimicrob Agents Chemother 2007 51:3510-3515.

20. Falagas ME, Kasiakou SK, Rafailidis PI, Zouglakis G, Morfou P: Comparison of mortality of patients with Acinetobacter baumannii bacteraemia receiving appropriate and inappropriate empirical therapy. J Antimicrob Chemother 2006, 57:1251-1254.

21. Shorr AF, Micek ST, Kollef MH: Inappropriate therapy for methicillin-resistant Staphylococcus aureus: resource utilization and cost implications. Crit Care Med 2008, 36:2335-2340.

\section{doi:10.1186/1471-2334-14-513}

Cite this article as: Hanberger et al:: Infections, antibiotic treatment and mortality in patients admitted to ICUs in countries considered to have high levels of antibiotic resistance compared to those with low levels. BMC Infectious Diseases 2014 14:513. 